\title{
Embodying Teaching: A Body Pedagogic Study of a Teacher's Movement Rhythm in the 'Sloyd' Classroom
}

\author{
Joacim Andersson ${ }^{1}$ (D) Jonas Risberg ${ }^{1}$
}

Received: 3 August 2017/Accepted: 2 March 2018/Published online: 24 April 2018

(C) The Author(s) 2018

\begin{abstract}
The article draws on body pedagogics and considers that teaching and learning experiences and outcomes are directly related to the different characteristics of movement behaviour. In this article movement behaviour specifically centres on a sloyd (handicraft education) teacher's walk through the classroom. The analysis illuminate the specific teaching use of the body as a spatial, temporal and situational movement rhythm in the classroom and how teachers and pupils tune into educational discourses by means of different body techniques. A wireless GoPro camera was attached to the teacher's chest in order to gain detailed view of pupil-teacher-body-material-tool encounters and a specific visual perspective of the sloyd teacher's walk. During a 2.5 years fieldwork, 25 wood-metal sloyd lessons were observed and recorded (circa $50 \mathrm{~h}$ of video). The study is informed by Dewey's embodied theory of learning and focus the alternation between active and passive phases in the stream of experience. From such Deweyan perspective the rhythm of an activity for organising experience, is fundamental to the creation of intelligent moving habits. The results show the body pedagogic experiences, outcomes and means by highlighting the teacher's (a) spatial path by describing mutual relationships between the material arrangement of the classroom, the teacher's bodily movements and the pupils' participation in the lesson, (b) temporal pace by his 'flights and perchings' through the lessons and how he moves from pupil to pupil and assignment to assignment, (c) specific pacts by describing body techniques and situated teacher-pupil encounters that terminate in an agreement about how to proceed.
\end{abstract}

Keywords Body pedagogics $\cdot$ Habit $\cdot$ Dewey $\cdot$ Rhythm $\cdot$ Video research

Joacim Andersson

joacim.andersson@edu.uu.se

1 Uppsala University, Box 2136, 75002 Uppsala, Sweden 


\section{Introduction}

This article contributes to educational knowledge about the environment of embodied action (e.g., Shilling 2017) to the growing field of body pedagogics. Inspired by an increasing interest in the embodied dimensions of learning and education (Hockey and Allen-Collinson 2007; Shilling 2007, 2018) and how 'movement' has recently been utilised as an analytical object both to investigate learning in school (Larsson and Quennerstedt 2012; Almquist and Quennerstedt 2015; Franks and Jewitt 2001) and to reconsider fieldwork practice (Pink 2011; Pierre and Macleod 2010), we consider that teaching and learning experiences and outcomes are directly related to the different characteristics of movement behaviour (e.g., Sheets-Johnstone 2011; Johnson 2007; Shilling 2008). In order to further illuminate movement in relation to body pedagogics and classroom research, in this article movement behaviour specifically centres on a teacher's walk through the classroom.

Video recordings of a teacher's movement (specifically walking, stopping, starting, turning and so on) in the classroom, collected during a five term long fieldwork of wood and metal craft lessons (part of the Swedish school subject 'sloyd'), have been examined and analysed. This first-person view of movements in the classroom and of pupil-teacher-material-tool encounters was facilitated by a wireless GoPro camera attached to the teacher's chest (e.g., Chalfen 2014; Lloyd 2016). By following the video ethnographic principle of regarding the camera lens as an analytical distinction (Ochs et al. 2006; Mondada 2006), this tool provides us with a specific visual perspective of walking with the teacher.

Body pedagogics is increasingly discussed in formal and informal education (Shilling 2007, 2010, 2017). Various empirical studies have suggested and argued for the notion of bodies as transactional (Andersson and Östman 2015; Quennerstedt et al. 2011; Maivorsdotter and Wickman 2011), i.e., a view of the body as an organic collection of activities "characterized by habit and grounded in physicality that is constituted by its relationships with its various environments" (Sullivan 2001 , p. 40). Important to the body pedagogical framework of this study is that the sloyd teacher's walk is considered as a certain teaching habit and a purposeful moving through a specific terrain. This specific teaching use of the body is analysed as a spatial, temporal and situational movement rhythm in the 'sloyd' classroom; a rhythm that facilitates synchronicities between 'the other' and the 'the self' that are of crucial importance in sloyd education.

Following the principles of "rhythm analysis" (Lefebvre 2004), empirical attempts have been made to impose rhythm on bodies in studies focusing on how people's trajectories separate and cross in regular ways (e.g., Lande 2007), for instance how walking rhythm as a social behaviour continuously adapts to particular circumstances like public spaces, traffic rhythms, working life and weather rhythms (Edensor 2010). From the body pedagogics perspective of this article, the analysis of how human beings polyrhythmically adapt to different circumstances is posed as an educational research problem (e.g., Ryan 2011). 
The last decade of research on body pedagogics is relevant to our general understanding of education and pedagogy. This growing analysis tradition suggests that as embodied beings intentionally situated in specific environments, we are capable of both securing and transforming existing habits and cultural customs (Shilling 2017). The important notion of body pedagogics in relation to rhythm, habit and experience (e.g., Lande 2007; Shilling 2008; Crossley 2005; Andersson and Östman 2015) is that people do not simply march to their own beat, but use and create different means, cultivate different experiences and actualise and appreciate different outcomes in relation to each other. In much the same way as urban life can be analysed through complex polyrhythmic patterns, the learning environment in classrooms can be analysed through the spatial and temporal pattern of how teachers and pupils tune into educational discourses by means of different body techniques.

\section{Background}

Over the past two decades, embodiment research in philosophy (e.g., Lakoff and Johnson 1999; Johnson 2007; Sheets-Johnstone 2011; Sullivan 2001), psychology (e.g., Todres 2007; Brown et al. 2011), sociology (e.g., Shilling 2012; ScheperHughes and Wacquant 2002; Sennett 2008) and education (e.g., Evans et al. 2009; Shilling 2007; Hockey and Allen-Collinson 2007) has contributed to an expanded recognition of the embodied dimension of teaching and learning. Furthermore, embodiment research highlighting learning and movement has itself been enhanced by frameworks that recognise lived experience and the interactions between human beings and their social, material and symbolic world (Crossley 2006; Calhoun and Sennett 2007; Lefebvre 2004). Phenomenology and pragmatism stand out as the most influential traditions in this context (Shilling 2017; Brown and Payne 2009). Against this background, in this study three areas of research, all including pedagogics and embodiment, are important for contextualising the teacher's movement in and through the classroom.

Firstly, a wide range of research on embodiment with regard to occupational learning and apprenticeship (e.g., Hassard et al. 2000; McDowell 2011; Lave 2011, 2012), sport pedagogy and health (e.g., Crossley 2006; Evans et al. 2008; Quennerstedt 2013; Andersson et al. 2016) and religious and lifestyle projects (e.g., Mellor and Shilling 2014; Wacquant 2004) have paid attention to how and why specific meanings of the body and embodiment are created in different contexts and cultures. Although this research helps us to understand our personal and collective embodied processes at work, in our spare time and in education in a late modern era (e.g., Sennett 1998; Calhoun and Sennett 2007; Shilling 2005; Joas 1996; Evans et al. 2008), there is a purported risk of positioning the body as a transcendent force and neglecting other important phenomena, such as meaning-making, interaction and reflective thought (Crossley 2007; Pink 2011; Shilling 2010, 2017). In this context, a body pedagogics approach takes the transactional relationship between organism and environment seriously and suggests that we recognise how pedagogical means, embodied experiences and habitual outcomes are shaped to meet the interactive exigencies of specific situations (Shilling 2010; Crossley 2005; 
Andersson et al. 2015). This study closely connects to a marginalised part of body pedagogics research that analytically emphasises rhythm. When studying the reflexive body techniques of circuit trainers, Crossley (2004) notes the importance of rhythm between instruction and physical movement, and concludes, "the playing of music aids in the construction of this intercorporeal order" (p. 46). Likewise, Lande (2007) describes how soldiers are trained to run, shoot and patrol by means of breathing rhythm: "when bodily consensus of breathing fails we see the coherence of social interaction and the "mutual-tuning-in' ... of bodily rhythms fall apart" (p. 100). In our analysis of the sloyd teacher's walk, we emphasise how the teacher and the pupils in the sloyd classroom synchronise and assimilate different rhythms and environments into their bodily capacities of movement and anticipation.

Secondly, classroom studies conducted in different educational traditions have focused on the interplay between governing rules and values, school practices and teacher-pupil interactions. In the classroom ecology paradigm (e.g., Doyle 1977, 1986), classrooms are viewed as interrelated systems in which change in one system influences action in another (Hastie and Siedentop 2006). Such conditions urge teachers to find strategies that reduce the complexity of the classroom environment (Leriche et al. 2016). For instance, in classroom research developed in the French didactic research tradition (e.g., Amade-Escot 2006), scholars have used the concepts of 'didactical contract' and 'didactical milieu' to better understand how didactic situations function and how social, conceptual and material components, together with semiotic aspects, influence the school's learning environments (Leriche et al. 2016). In addition, drawing on Bernstein's (1990) suggestion that pacing is an important part of the framing and classification of school practice, Morais (2002) shows that from a micro level perspective of classroom activity, a weak framing of pacing is important, because it allows children to gain control over their acquisition of knowledge. A weak classification of spaces and discourses is also vital for the creation of a context in which children can question, discuss and share ideas. Moreover, in relation to pace (to acquire subject specific content) and space (to develop critical and interactional skills), Morais (2002) note that changing pedagogical principles and ideology may be more efficient than increasing the amount of time that children spend at school. Thus, the ecology paradigm, research focusing on didactical milieu and contracts and a micro level classroom analysis of Bernstein's principles of categorisation and framing indicate that strategies that infringe the learning environment and control the pace and space of knowledge acquisition are not simply structural problems, but aspects that need to be analysed in relation to interactional patterns and specific teacher habits. By adding an embodied dimension to this complexity of school practice and classroom activity, we note that the early works of Birdwhistell (1970) and Sheflen (1972) show how relationships between body movement and educational environment are systematic and sequenced and establish communicational structures that can reinforce, complement, or contradict verbal instruction. A number of micro ethnographic studies have also examined how posture and conversational rhythm shift between different classroom contexts (Mehan 1998). The growing research interest in body pedagogics (e.g., Andersson and Östman 2015; Andersson et al. 2016; Andersson and Maivorsdotter 2016) and didactical research on embodiment 
(e.g., Larsson and Quennerstedt 2012; Pierre and Macleod 2010; Almquist and Quennerstedt 2015; Franks and Jewitt 2001; Håkansson and Östman forthcoming) suggests a need to further explain and explore movement and embodied rhythm in the context of classroom activity. This would facilitate the acquisition of knowledge about the environment of embodied action and how the pace and space of knowledge acquisition can best be conducted.

Thirdly, in handicraft-oriented education such as 'sloyd', empirical research has approached learning as certain master-apprentice relationships (e.g., Nielsen and Kvale 1999; Marchand 2008, 2010b) and a gender and culture bound process (Illum 2006; Sigurdsson 2014). Different academic disciplines have contributed knowledge about the development of conceptual tools and empirically grounded analyses of particular craft activities (Sennett 2008; Marchand 2010a; O'Connor 2007; Illum and Johansson 2009). In this respect, important results have been obtained against the background of Merleau-Pontian informed research and studies highlighting a wider temporal and cultural understanding of human development in craft professions. A rhythm approach to classroom activity, undertaken by following a sloyd teacher's walk using an action camera mounted to the person's chest, further develops important aspects of classroom research, such as pacing (Bernstein), spatial and temporal arrangements (Franks and Jewitt 2001; Pierre and Macleod 2010) and teacher-pupil interactions (Mehan 1998; Charalampous and Kokkinos 2013). In this context, the Swedish school subject of sloyd constitutes a rich case for the further development of methods and analyses that foreground the body and its relationships to material, technical and social aspects of classroom teaching.

\section{Method}

\section{The Setting}

The article is part of a larger project aimed at generating knowledge about pupils' learning of practical embodied knowledge in the context of sloyd and physical education. In this project, video-ethnographic fieldwork, including observations and interviews, was conducted at a Swedish secondary school. The school and two particular classes were visited frequently for five terms from 2015 to 2017. The school, a middle-sized municipal secondary school in a small Swedish town, accommodates around 600 children aged 13-16 (3 year grades and 15 classes) and 40 teachers. There are about 28 pupils in the classes observed in the study. Sloyd lessons are scheduled for $1 \mathrm{~h}$ a week and the classes are divided into two groups, each with approximately 14 pupils. Each term the groups alternate between woodmetal sloyd and textile sloyd. For the purpose of this article, only the wood-metal lessons are studied.

The overall aim of Swedish sloyd is to develop pupils' abilities to generate ideas, consider different solutions and judge the results by allowing them to engage in craft processes (Swedish National Agency for Education 2011). Hence, in the sloyd lessons, pupils are expected to accomplish very practical and individual tasks. 
Before elaborating on the recordings and the analysis, some of the prerequisites for the study's empirical data need to be noted.

First, each term the lessons include one or occasionally two specific assignments. These assignments are designed to give the pupils sufficient direction to work on a defined product and the freedom to suggest individual solutions. For example, in the first term the pupils are asked to make a name plate by carving a word of their choice into a piece of wood and in the second term to form metal pieces into different figures illustrating human activity. Even though all the pupils are given the same assignment (i.e., wooden plate), each project evolves differently, mainly due to the pupils' freedom to elaborate individually in all the stages of the crafting process. This results in a diverse teaching environment, in the sense that one pupil may need help with carving, another may need to ask questions about painting and a third may need instructions about how to drill.

Second, the same teacher, here called Don, is in charge of each of the observed sloyd lessons. Don is a middle-aged experienced teacher and he appears to be liked and trusted. Even pupils not attending the class occasionally come into the classroom for a chat to share their problems or successes with him. Also, very few occasions are observed in which Don explicitly disciplines the pupils in order to maintain order.

Thirdly, the sloyd classroom is open-spaced with a number of workbench islands grouped four on four. This setup allows for peer-collaboration and support, as well as intervention and disagreement about how to carry out the recommended courses of action. Some smaller adjacent rooms are available for certain activities, such as painting, plating and soldering, although most of the crafting procedures are carried out by the pupils at their workbenches (Fig. 1).

\section{Recording}

In connection with learning studies, and more specifically with the field of classroom research, the use of video recordings has proved useful in a number of different contexts, ranging from single-case qualitative to large-scale quantitative studies (Goldman et al. 2007) and including various school subjects (e.g., Clarke et al. 2006; Plowman and Stephen 2008; Janík et al. 2009; Fisher 2012). The point of departure for this study is that movement and embodied rhythm are inevitable parts of the everyday practice of teaching. Thereby, aligning with naturalistic studies of everyday life in the classroom (e.g., Mehan 1979; Hester and Francis 2000), the analytical spotlight is on 'naturally occurring' situations that uniquely originate, unfold and disperse.

Using a video camera accentuates the methodological considerations-not only about the importance of being in the field, but also of aspects such as camera position and angle. For example, at the point of video analysis, the situation at hand is both relayed and restricted by the microphones and the camera lens. On the other hand, video recordings can be slowed down or speeded up, which facilitates a closer study of a complex situation (Heath et al. 2010). Traditionally, video based research uses camera positions and angles that represent the non-participating researcher, or that capture a bird's-view of the situation (either static or dynamic), which makes it 


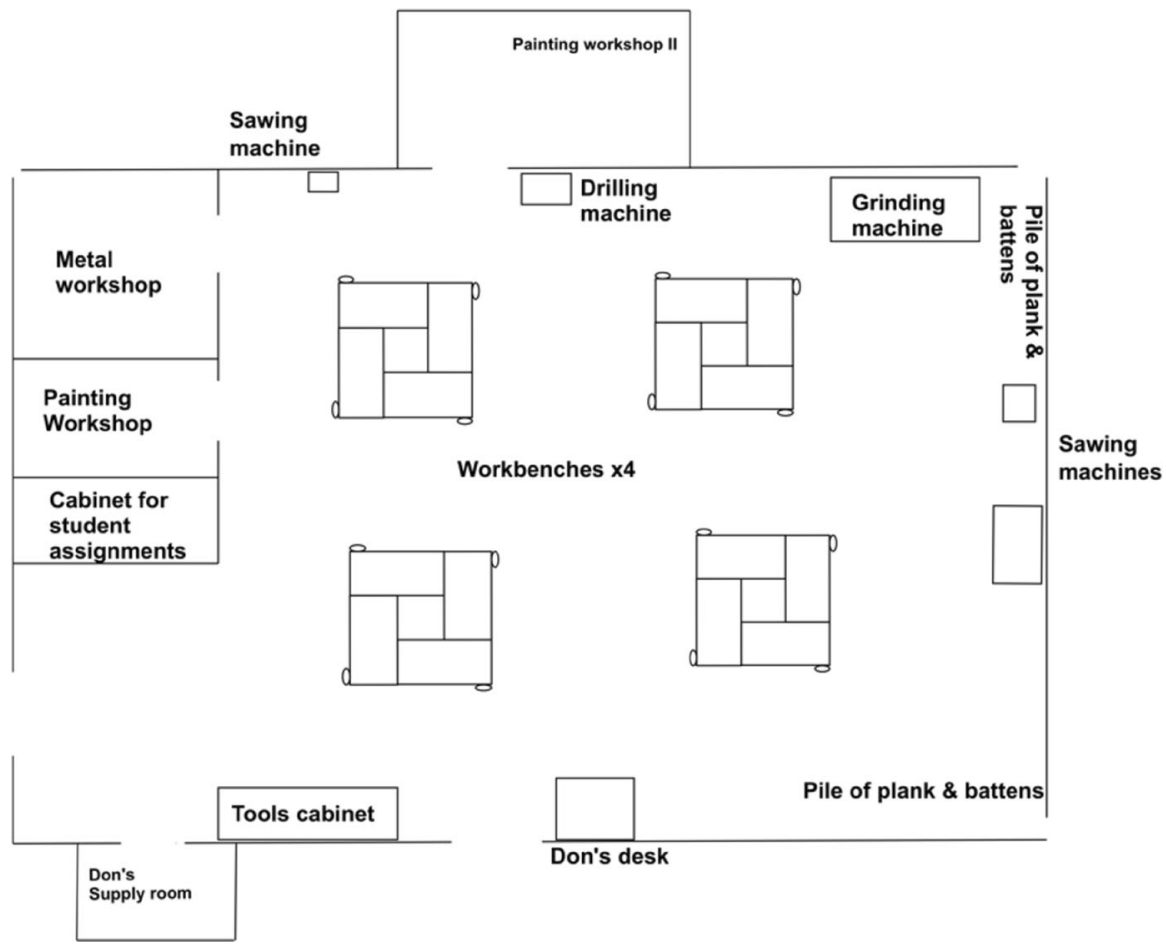

Fig. 1 The school's sloyd classroom

possible to study multimodal details such as bodily postures, gestures, gazes and facial expressions (Mondada 2006; Stivers and Sidnell 2005). This traditional camera set-up reflects how the researcher "finds and frames the event in an embodied way" (Mondada 2006, p. 58). However, in this study, a wireless GoPro camera is attached to the teacher's chest (Fig. 2) in order to gain a close-up and detailed view of pupil-teacher-body-material-tool encounters and a specific visual perspective of the sloyd teacher's walk. ${ }^{1}$

During the fieldwork, 25 wood-metal sloyd lessons were observed and recorded, which resulted in more than $50 \mathrm{~h}$ of video.

\section{Analytical Steps}

According to the limited vision that follows from viewing events through a camera lens, the described camera setup constitutes the first analytical step. From this analytical position, the video material is analysed using an open-mind approach previously described as a phase of "unmotivated looking" (Psathas 1995, p. 45). These two steps (the camera view and the "unmotivated looking") of visually taking part of and identifying certain details of the sloyd data result in a genuine

\footnotetext{
1 In this study an additional camera was set up to get an overall picture of the classroom and the activities and to focus on particular teacher-pupil and pupil-pupil interactions.
} 
Fig. 2 The GoPro attached to the teacher's chest

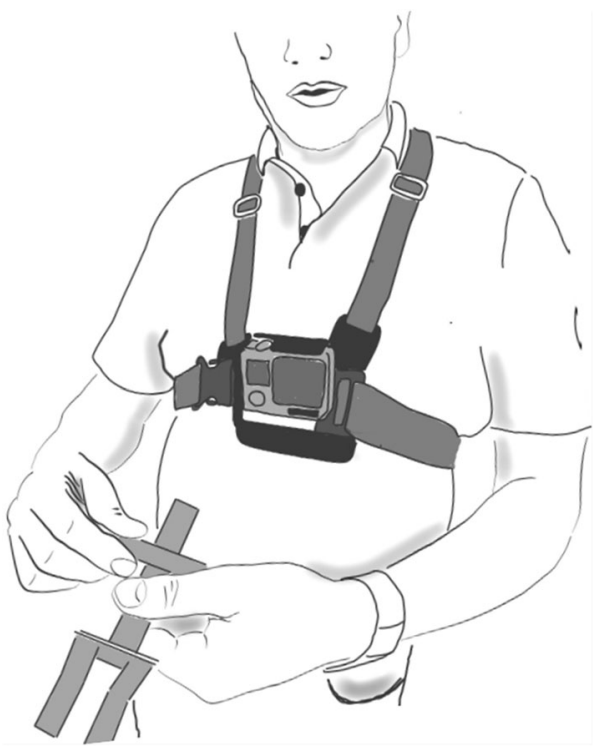

physical experience for the researchers. The continuous movement of the teacher in the video, his turnarounds, bends, leans, stops and starts create an instant and dizzy feeling at the researcher's desk. When the teacher walks forwards, backwards and turns around, the pupils, tools, material and furniture pass swiftly by. Thus, the immediate and bodily experience of watching the recordings gradually structure the observations and further influence a third step, in which specific data is selected from the video corpora (cf. Derry et al. 2010). In these first three steps, the GoProview reinforces the embodied actions that had remained unnoticed in the recordings made by the traditional camera set-up.

Other analytical steps include following the teacher's walk step by step to identify a pattern, moment by moment to identify, count and measure the 'stopsand-starts' (teacher-pupil encounters) and situation by situation to identify the embodied techniques used by the teacher in the process of reaching agreement with the pupils about their assignments. Against this background, a three-layered disposition is constructed to describe and structure the means, experience and outcomes of the teacher's walk in connection with a spatial path, a temporal pace and situated agreements that we call pacts. 10 Lessons are studied to create the path, 1 lesson to create the pace and 15 lessons to select a number of pacts of specific interest for embodied action and rhythm.

\section{Theory}

\section{Movement and Rhythm Habits}

The notion that physical activity does not just enable or constrain, but can alter the capacities and identities of individuals and the environment they inhabit, is central 
to body pedagogics (Shilling 2017; Mellor and Shilling 2010; Andersson and Garrison 2016). This mutual accommodation between individuals and their physical environment is also an important landmark in James' and Dewey's concept of experience and habit. To elucidate knowledge as a practical accomplishment grounded in embodied experience and habit-formation, James claims that "no one can walk across the platform at a public meeting with just the same muscular innervation he uses to walk across his room at home" (1884, p. 195). Similarly, Shilling (2008) argues that movement is important to body pedagogics and points out that human beings' reflexive and habitual adaption to their physical surroundings is evident in the ordinary activity of walking:

As people make a pathway or route familiar, through repeatedly traversing a terrain, they do not simply become aware of its bends, bumps and directions, but actually assimilate these into their bodily capacities of movement and anticipation (p. 86).

Analytically foregrounding movement can elucidate the rhythm of the alternation between the active and passive phases of experience, which lies at the core of Dewey's embodied theory of learning (Garrison 2009, 2015). Comparing this to the advance of an army, Dewey declares that if we move too rapidly "we get away from the base of supplies - of accrued meanings" and the experience becomes flustered and confused. On the other hand, if we dwell too long in a consummatory/appraisal phase we lag behind and "experience perishes of inanition" (1934/2005, p. 58). When finding the rhythm between the gains of supply and the gains of advancement, habits work functionally and "each resting place in experience is an undergoing in which is absorbed and taken home the consequences of prior doing, and, [...] each doing carries in itself meaning that has been extracted and conserved" (1934/2005, p. 58). Thus, in the search for a recommended course of action, the development of our experiences is somehow dependent on a rhythm of a series of doings. Dewey elaborates on this rhythm in relation to 'criticism' and 'appreciation' in Experience and Nature:

When criticism and the critical attitude are legitimately distinguished from appreciation and taste, we are in the presence of one case of the constant rhythm of perchings and flights" (to borrow James' terms), characteristic of alternate emphasis upon the immediate and mediate, the consummatory and instrumental, phases of all conscious experience (1958, pp. 399-400).

In Dewey's view, extreme versions of "criticism" (reflective thought) and "appreciation" (consummatory experience) ignore James' insights into the omnipresent rhythm of perchings and flights in the stream of experience (1958, p. 400).

The rhythm of succession of the two modes of perception ['criticism' and 'appreciation'] suggests that the difference is one of emphasis or degree. Critical appreciation, and appreciative, warmly emotionalized criticism occur in every mature sane experience (1958, p. 401). 
From this it follows that the rhythm of an activity for organising experience, is fundamental to the creation of intelligent moving habits (Garrison 2001). In this case, a GoPro view of the teacher's walk has enabled us to follow how the teacher conducts pupils' "alternate emphasis upon the immediate and mediate" (1958, pp. 399-400) experiences into an ordered sloyd learning rhythm by alternating between engaging in a critical problem solving activity (i.e., 'innovative thinking'/ reflexive thought) and adhering to a base rhythm (appreciative use of a certain walk).

\section{The 'Wholeness' of Experience}

A sloyd education environment is filled with bodily engagement and changing social, material and instructional conditions. When describing such artistic activity, Dewey relies on the omnipresent rhythm of perchings and flights, i.e., an alternation between the active and passive phases of human experience. Johnson (2007) explains this by referring to how the "flow of experience comes to us as unified wholes (gestalts) that are pervaded by an all-encompassing quality that makes the present situation what and how it is" (p. 73). Sustaining a rhythm between "perchings and flights" in the stream of experience could be described as experiencing an activity as a unified whole. In this sense, Dewey accounts for experience in existential terms and points to how we are engaged in the rhythm of an activity (Hickman 1992, p. 20; Garrison 2011). Studying a functional habit such as walking with a GoPro camera setup, and organising embodied actions in accordance to a spatial path and a temporal pace, could also be considered as the operationalisation of an existential dimension of teaching. Particulars, analytically identified as situated 'pacts', then appear as discriminations in these existential experienced wholes and how teacher and pupils selectively attend to specific things according to a certain movement rhythm.

\section{Habits and Selective Attention}

The existential world in which we live includes the situations in which we "find" ourselves and "the means and instruments that we utilize to alter these situations and accommodate ourselves to them" (Hickman 1992, p. 24). 'Selective attention' points to a purposeful dimension of the rhythm of "perchings and flights" in the stream of experience in which "we are discriminating within a situation that was given to us as a whole" (Johnson 2007, p. 75). When an experienced whole is vague, "discriminating" does not just mean a critical inspection of the traits of a problematic situation, but also a search for a tool to use in that situation. The purpose of the tool is to reorganise the experience in order to overcome its disparity. Thus, habits are tools for grasping and handling, form our interest and "working capacities" (Hickman 1992, p. 16), refer to material artefacts and are understood as "a recommended method or course of action" (Hickman 1992, p. 21). To analyse the environment of embodied action in the context of sloyd education, we therefore approach the teacher's walk as a teaching tool (i.e., an intelligent habit) that functions dynamically, "supplying inner tension, like mainsprings, and, like 
flywheels, ... also supply the momentum necessary for continued activity even in the absence of stimuli that call for innovative thinking" (Hickman 1992, p. 16).

To become familiar a route needs to be given attention. A leisurely walk through the forest to look for mushrooms differs from the walk of a soldier trained to identify and localise danger. Likewise, a teachers 'walk' in a classroom to attract pupils' attention, respond to their questions and impart information is different from the same teacher's 'walk' across his or her living room at home to tell the children that dinner is served. Expressed in the terms of body pedagogics, in these situations the 'walkers' have learned to use different means, coordinate different experiences and appreciate different outcomes. In this sense, habits afford us with "the means and instruments that we utilize to alter these situations and accommodate ourselves to them" (Hickman 1992, p. 24). Moving in an environment does something to us. Making a route familiar involves assimilating the environment into our bodily capacities and the consequences that our actions may have on it.

Using specific means for an end and being aesthetically wise about the consequences means having an intelligent movement habit that alters an environment and accommodates to it. Here, habits do not only reproduce practice for specific aims, but also produce "something new as a means of changing situations that are not what we wish them to be" (Hickman 1992, p. 41). In a classroom context, the environment mostly consists of pupils being actively engaged in traversing the educational terrain and making progress in their assignments. Highlighting the spatial path, temporal pace and situated pacts of a teacher's movement habit as a central feature of a learning environment takes the rhythm between the active and passive phases of experience seriously.

\section{Analysis/Findings}

The analysis of Don's walk is a trisection of its different layers during a sloyd lesson. First, the spatial path of his walk is followed in order to highlight the mutual relationship between the material arrangement of the classroom, his bodily movements and his and the pupils' participation in the lesson. Second, the temporal pace is elaborated in order to describe Don's flights and perchings through the lessons and how he moves from pupil to pupil and assignment to assignment. Third, pacts illustrate specific and situated teacher-pupil encounters that terminate in an agreement about how to proceed. The order of the path, pace and pact is important in order to operationalise the Deweyan standpoint to always begin in the full richness of experience. Hence, pacts are explained against the background of the spatial and temporal coordination of Don's walk, rather than as isolated islands of important meaning-making.

\section{The Path: Spatial Movement}

Don prepares for the class by retrieving and checking the equipment and by updating himself about the class and their assignments. When everyone is gathered 
he stands at the front of the classroom, talks to the class as a whole and refers to earlier lessons and instructions (Fig. 3).

The gathering in the classroom, how Don and the pupils position themselves in relation to each other, Don's introductory talk and the pupils' attention are embodied actions that contribute to a collective embodied experience of starting a common lesson. After this the pupils retrieve their individual assignments and materials from the previous week and begin to work independently. Don, who is by now traversing the terrain of the classroom, immediately becomes involved in what is going on. He walks through the classroom and stops to discuss various problems with different pupils. When the issues are solved, dissolved or temporarily put on hold, he walks to the next pupil, the next bench and the next assignment. The image below spatially illustrates the transition from the common start to individual instruction by tracing and manually plotting Don's walk through the classroom (Fig. 4).

Following Don's movement habit through the GoPro lens, the sloyd activity as a 'whole' is realised piece-by-piece. He engages himself by overhearing or anticipating trouble in the myriad of ongoing projects. Passing the tin plate room enables him to determine the activities at a glance, for example by the distinct sound of someone sawing or a recognisable smell. Don's experience senses seem to detect trouble before it occurs. The pupils incorporate Don's path and position as a part of their environment and indicate their need for help, for instance by shouting out to him, entering Don's field of vision, or queuing up to speak to him. The transcript below (transcript 1) illustrates how Don's walk structures the pace and space of the assignments and how the pupils' communicating actions and crafting processes reciprocally structure Don's walk.

Described as a mutual accommodation between organism and environment, Don's professionalism in the sloyd classroom is not simply about his awareness of pupils' needs, desires, means, experiences, skills, attitudes, interaction patterns, etc. It is also a description of how he assimilates these into his bodily capacity of movement and anticipation. In this sense, his habit of moving in the sloyd classroom stands out as a reflexive teaching tool. Don's walk during a 60 min lesson is illustrated in Fig. 5.

As a reflexive teaching tool, his walking teaching helps him to discriminate holistically, i.e., attend to the right qualities, find characteristics that allow something to be educationally done according to the lesson, attend to the assignments and to the pupil-material-tool encounters. By adding the walking paths from 10 lessons, layer by layer, the following picture appears (Fig. 6).

By foregrounding what might be dismissed as unfocused interaction, it is evident that Don's walking teaching is an important embodied aspect of how space relates to learning environments. Beside the benches, the most frequently visited spots are Don's desk and the tools cabinet. The sparsely visited area in the top right-hand corner is explained by the fact that pupils seldom work at these benches and that the grinding machine is not always used during class. Thus, the tool and machinery arrangements partly structure Don's walking teaching and thereby potentially influence pupils' possibility to participate in sloyd education (cf. 'space').

In conclusion, the path shows that in order to successfully participate in sloyd education pupils must learn to tune into Don's spatial movement, just as Don needs 


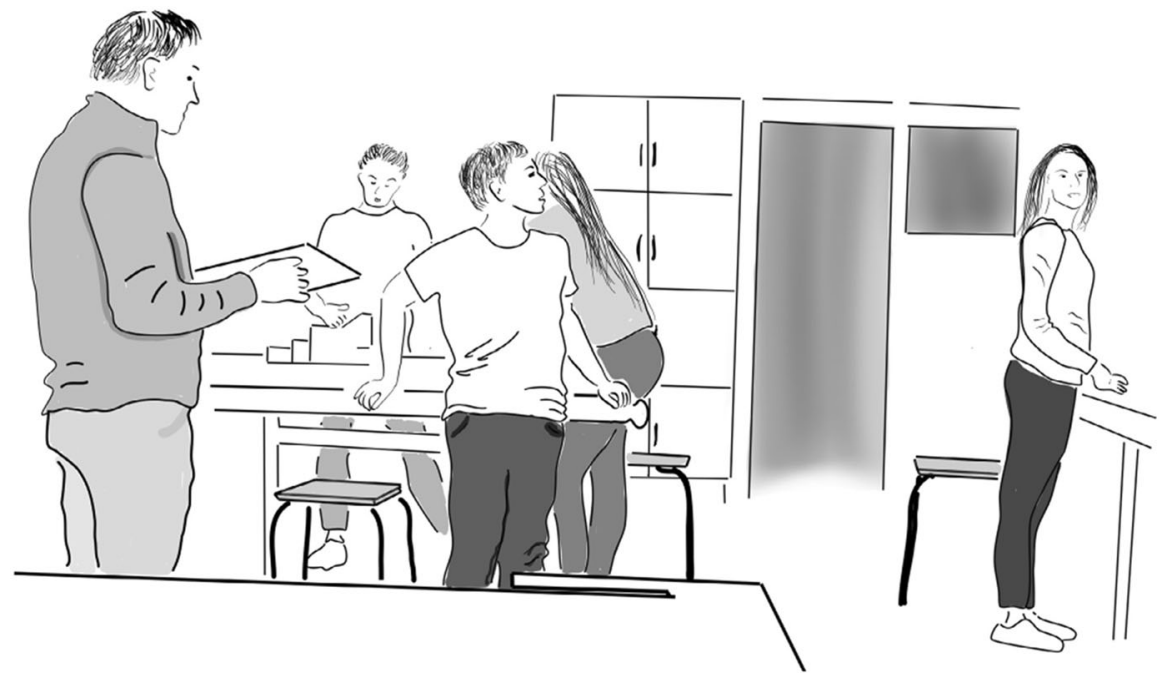

Fig. 3 The collective arrangement of starting a lesson

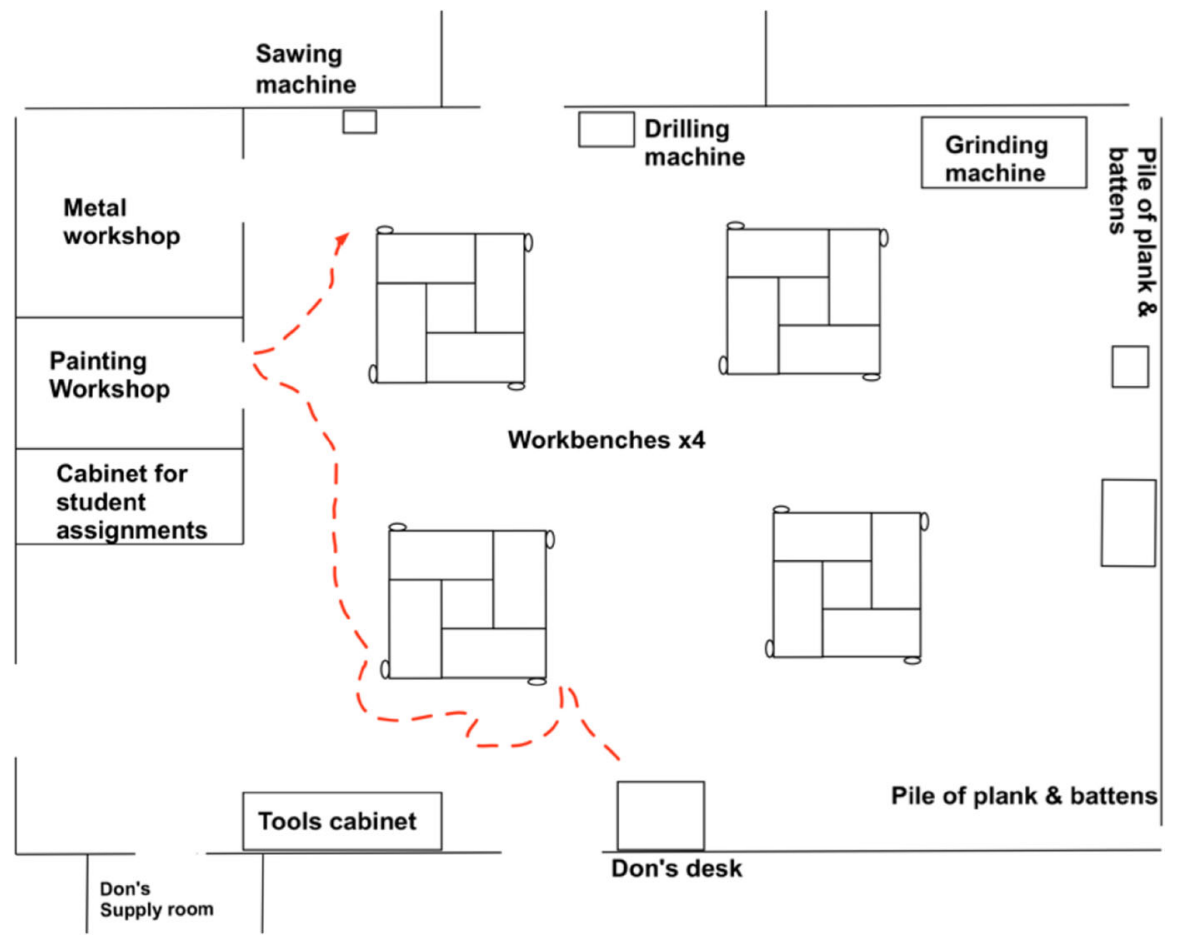

Fig. 4 Visualisation of Don's walk through the classroom 


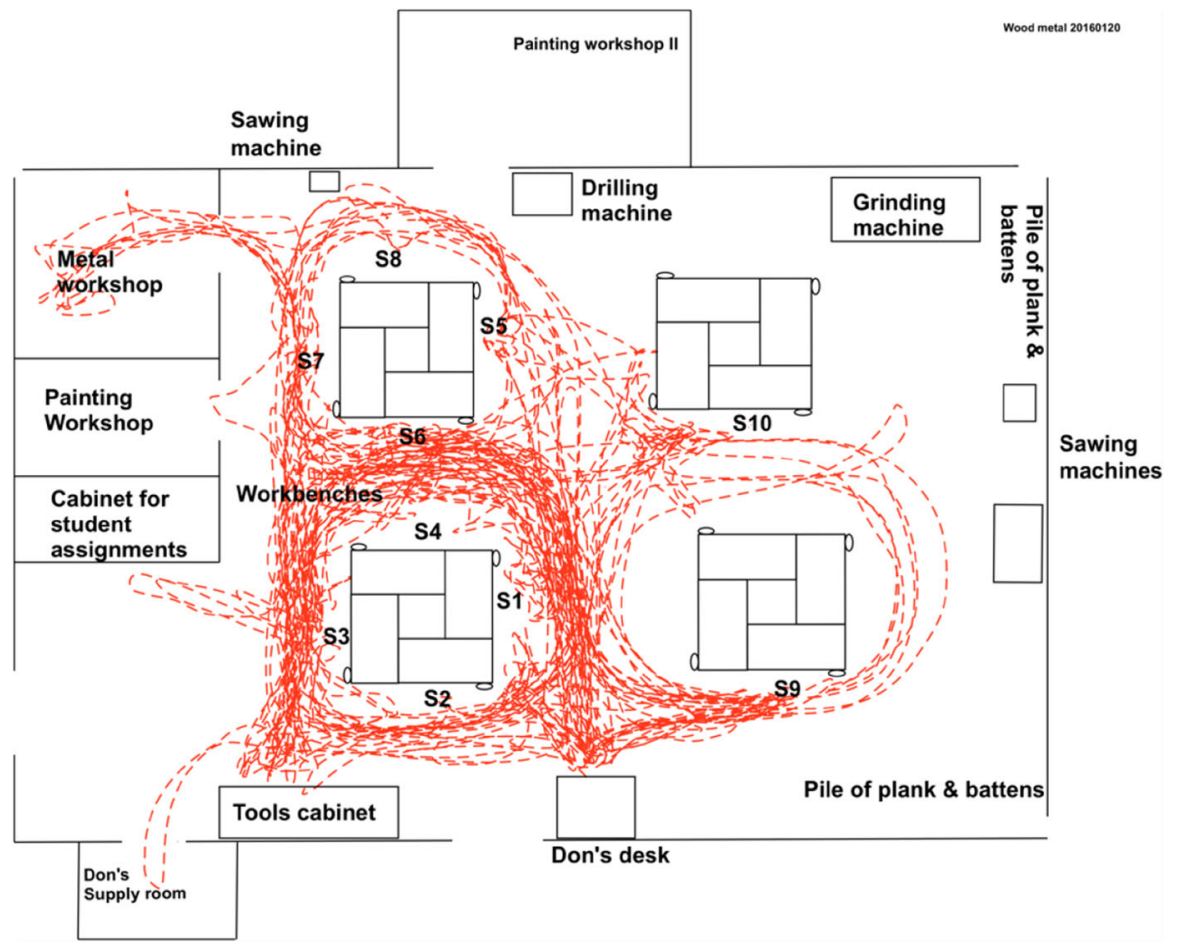

Fig. 5 Don's path in the classroom over the course of $60 \mathrm{~min}$

to tune into each pupil's assignment and how he or she progresses, performs and interacts. What the path of Don's movement habit does not show are the particular pupil-teacher encounters that educational research usually studies in the context of learning. In the pace, Don's movement habit is further described as an array of 'stops-and-starts' in the sloyd classroom.

\section{The Pace: Temporal Movement ('Stops-and-Starts')}

Flights and perchings refer to how the focus and context of action is formed by the alternation between active and passive phases of experience. In this study of the teacher's walk, context refers to teacher habit, while focus refers to particular teacher-pupil encounters.

When Don's walk is traced through the lens of the GoPro camera it is easy to measure the length of each focused encounter. By noting the name of the pupil involved, a distribution chart of Don's encounters can be created. The following chart shows an overview of the various lengths and distribution of teacher-pupil encounters during a 60-min lesson (Fig. 7). The ID of each pupil in the classroom (S1-S10) in indicated on the far left. The timeline of the lesson is indicated at the bottom of the diagram and the filled-in sections display the teacher-pupil encounters as they are measured. 


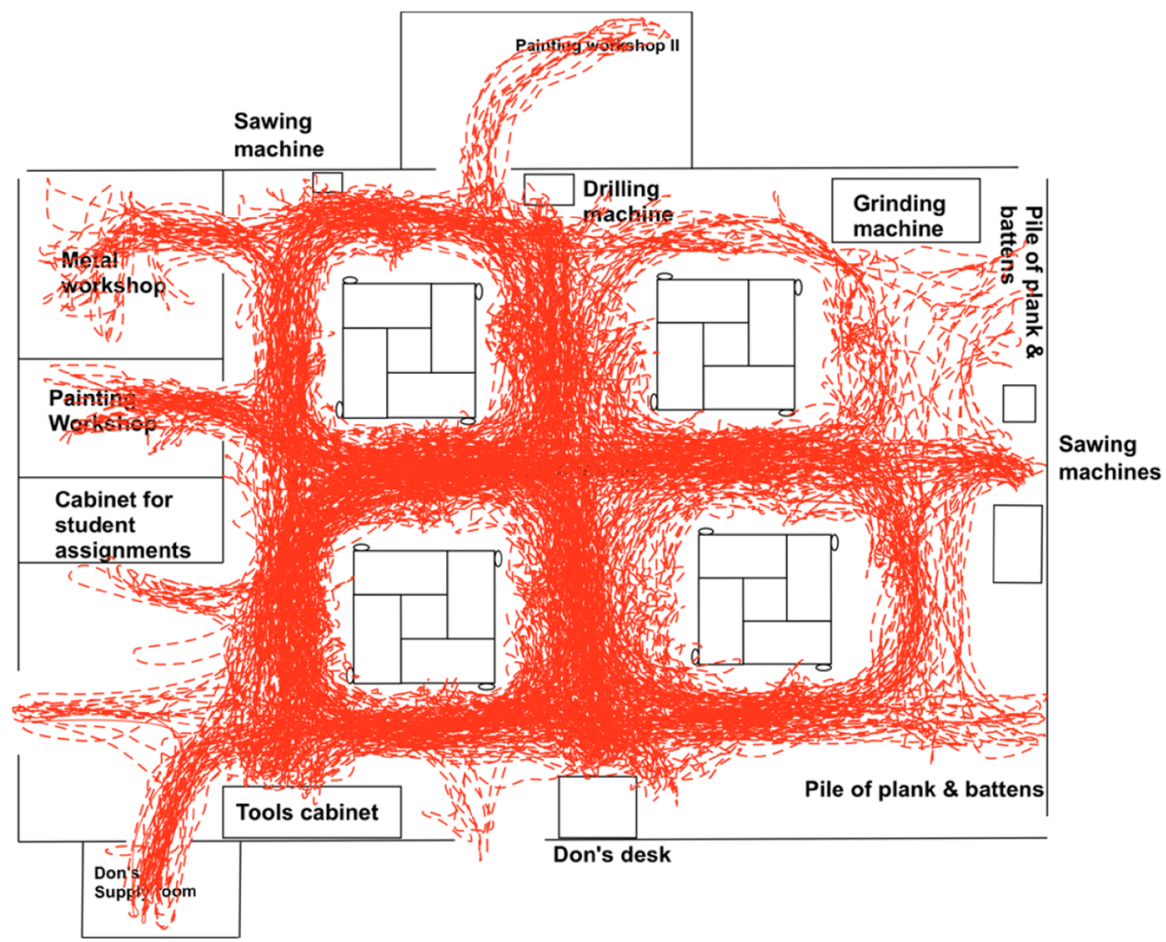

Fig. 6 The accumulated path of 10 sloyd lessons

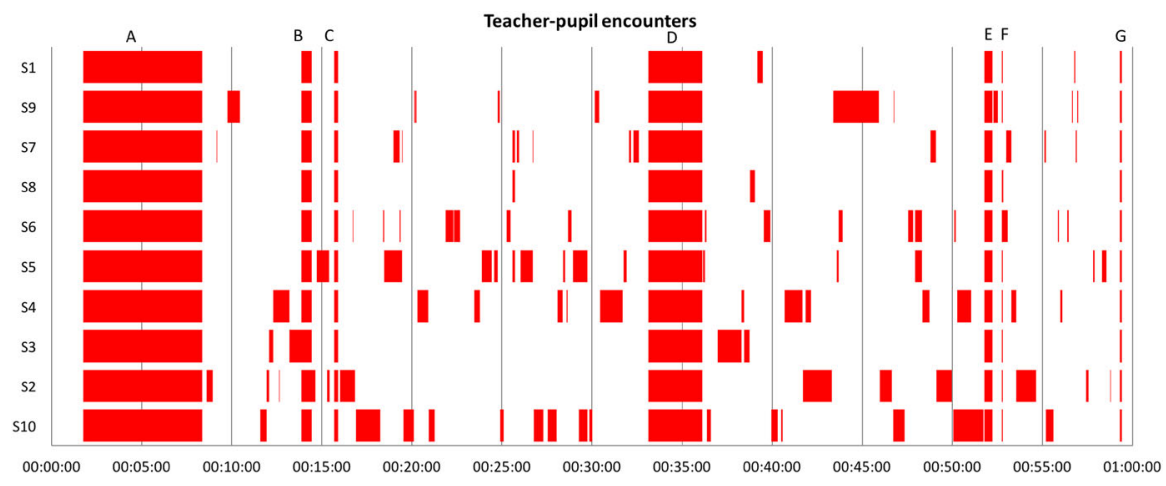

Fig. 7 Timestamps of stops and starts

The collective start of the lesson when Don talks to all the pupils in the class (spatially and bodily described according to path) takes $5 \mathrm{~min}$ and is illustrated in column $\mathrm{A}^{2}$ in the above chart. Likewise, the short talk that ends the lesson is illustrated in column $\mathrm{G}$ (at the $1 \mathrm{~h}$ interval). In-between the start and end of the lesson, Don engages in around 100 individual teacher-pupil encounters. Spatially,

\footnotetext{
${ }^{2}$ When Don talks to all the pupils an entire column is filled in the diagram.
} 
Don can be at rest in many of these encounters, in the sense that he puts down one tool (the movement transposition tools) and pick up another to address a pupil's particular problem. According to his transposition and shifting of tools, one of the things that Don is challenged by in his "stop-and-start" is the alternation between doing it for the pupils and tutoring the pupils. Against the background of an alternation between these different means, the scattered 'stops-and-starts' in the chart represent a certain pace of the classroom activity (on average 2.2 individual pupil encounters per minute).

According to the path analysis, Don moves forward step by step and does not leave pupils with too many ambiguities (loose ends-in-view). For example, if Don 'stops' for a long time to tutor individual pupils, the class as a 'whole' will lose crafting pace. On the other hand, if he habitually keeps his 'stops' and functional availability to a minimum and maintains the overall pace of the lesson, individual pupils will miss educative moments. The rhythm of this alternation is also evident, in that the pace occurs as a series of takeovers and that Don makes himself available to the pupils. Hence, to alternate between tutoring and functional availability he has to selectively attend to pupils' current situations by helping individual pupils and making himself available to others.

In Don's traverse of the terrain he also makes quick stops for collective guidance. He alone decides whether, when and where to gather the entire class for an intermediate common encounter. Don's transposition between common gatherings and individual instruction is traced in the chart. On five additional occasions during the lesson, Don gives instructions to the entire class (B-F), which allows for the maintenance of a common crafting pace. These intermediate talks may also reduce the number of individual encounters, in that he can address a number of problems and pupils at the same time. In the lesson shown in the chart, Don spends $11 \mathrm{~min}$ (18\% of the lesson) on such common encounters. Including the individual encounters (65\% of the lesson), Don spends $83 \%$ of the 60 -min lesson on focused encounters with pupils, which leaves only $10 \mathrm{~min}$ for transposition, sawing, collecting tools, etc. However, before attempting to understand an educational activity by focusing on and selecting a number of teacher-pupil encounters, the body pedagogics of the walking teaching need to be highlighted. In $1 \mathrm{~h}$ of teaching Don accomplishes hundreds of rapid 'stops-and-starts' and a few common gatherings. This indicates that the work of the teacher and the body pedagogics of school sloyd also includes a number of situations in which pupils engage in pupil-pupil encounters or "passively" hearing, looking and feeling.

Whereas the 'path' clearly describes Don's movement habit as a spatial 'whole', the 'pace' more explicitly describes temporal distraction and dispersion. However, in terms of a functional teaching habit, the various collective or individual 'stopsand-starts' hang together and form a significant context for every individual in the classroom.

In recognising the path of Don's walking teaching and the pace of the plurality of 'stops-and-starts', his particular way of creating short individual and group encounters stands out as a significant aspect of his own body pedagogics technique. The "stops" (focused encounter) are not necessarily tense, problematic or in need of complex deduction. Nevertheless, they do exhibit certain pervasive and qualitative 
experiences. Dewey explains that sometimes "we put our hands on the plow and turn back; we start and then we stop, not because the experience has reached the end for the sake of which it was initiated but because of extraneous interruptions or of inner lethargy" (1934/2005, p. 36). The chart showing the total number of Don's encounters and their scattered nature indicates that his movement habits include making short "stops" to help pupils, individually or collectively, when they need it. It also points to how Don assimilates the temporal conditions into his bodily capacity of movement and anticipation as a certain pace and walking rhythm.

Following the path and the pace of Don's movement habits, the full richness of the sloyd activity experience is realised moment-by-moment. By focusing on 'pacts', Don's movement habits are analysed in order to describe how the sloyd activity and its specific rhythm is realised situation-by-situation throughout his walk in the class.

\section{The Pact: Instructional Movement}

Each pupil's doubts about or difficulties with an assignment is a potential environment for Don. From a rhythmically body pedagogics perspective, this is explained by the path and pace of Don's movement habits, rather than by any mandatory responsibility for the pupils' learning. During his walking teaching, Don is involved in decisions, troubles and uncertainties related to the pupils' assignments and in that context shares immediate experiences. These situations are junctures, where pupils need Don's skilled habits and experiences as a professional teacher to move on in their crafting processes. Thus, the pupils must tune into Don's path and pace to take part in instructional events. During Don's walking path (Figs. 6, 9) the number of teacher-pupil encounters could exceed 100 (Fig. 7), which means that on average each pupil $(\mathrm{N}=10)$ encounters Don about 10 times. Presented in a boxplot graph (Fig. 8), the median and quartiles values of the length of the encounters add yet another layer of understanding of the sloyd learning environment.

The length of the encounters generally ranges from $2 \mathrm{~s}$ to $1.01 \mathrm{~min}$. Half of the encounters are less than $15 \mathrm{~s}$ and the other half ranges between 15 and $61 \mathrm{~s}$. As shown, the average time spent on encounters during the lesson amounts to $15 \mathrm{~s}$. Consequently, one obvious challenge for the pupils is to maintain focus despite this brief span of teacher attention. Another challenge relates to Don and the art of teaching. He has to support the pupils in their assignments, but should not stay too long with any one person and leave a number of others on hold. Hence, 'pact' refers to the activity of creating shared purpose in a recommended course of action in a spatial-temporal rhythm. By carefully looking at each focused encounter in a lesson, it is possible to identify, map and categorise the different pacts that Don and the pupils create. However, here the analysis is restricted to a number of encounters where Don and the pupils reach a common agreement about the next course of action in an explicitly embodied way. In the following we have chosen examples in which Don's actions always invoke a pupil's next action. It is this embodied actionreaction in the walking teaching that is indicative of the instructional nature of the lesson. 


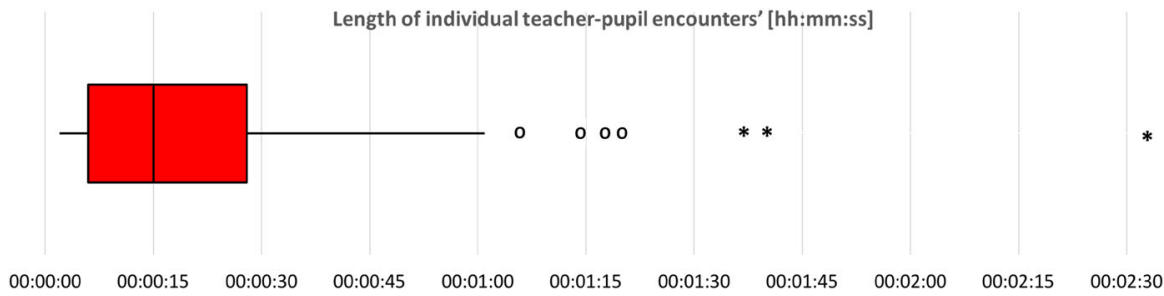

Fig. 8 Boxplot of time spent on each individual teacher-pupil encounter

Following Don's walking teaching from a GoPro viewpoint, it is recurrently visible that the pupils catch Don's attention as he passes by. Don can also invoke the pupils to join his path. One of the techniques registered in the video material is a 'join-my-path nudge'. This nudge is performed in various situations, but is typically preceded by a brief encounter in which Don and the pupil discuss what to do next. In such situations, Don invokes attention by entering the pupil's direct sphere and performing a short physical nudge with his hand, sequentially followed by a verbal utterance like "come here" or "follow me" (Fig. 9a-c). The snapshots below illustrate three situations in which the 'join-my-path nudge' is performed.

Don uses his body and physical movement to indicate a new direction and something to be followed. When he nudges the pupil he is already extending his path by walking in a new direction. Such verbal-touch-move actions indicate an engagement in certain courses of the crafting terrain relating to a pupil's specific assignment. Described as a process of creating ordered interest, the encounter highlights Don's control of the space and pace of the crafting rhythm and the pupils' traversing of the educational terrain in order to progress in their own assignments. By taking a certain course, they join each other's rhythms and accommodate themselves to a moving learning environment.

In the following section the 'educational nudge' extends to situations relating to instructional purposes and intuitive qualities. As a method of instruction, Don strikes the drill hole of a pupil's metal plate, thereby demonstrating how to judge a specific quality (Fig. 10a).

The pupil responds using the same technique (Fig. 10b), which we call 'sensing along', to judge the quality of the material. This results in a pact about an unsatisfactory sharp edge around a drilled hole. This explicit way of sensing along, where the body meets the material, is a recurrent technique that allows Don to help
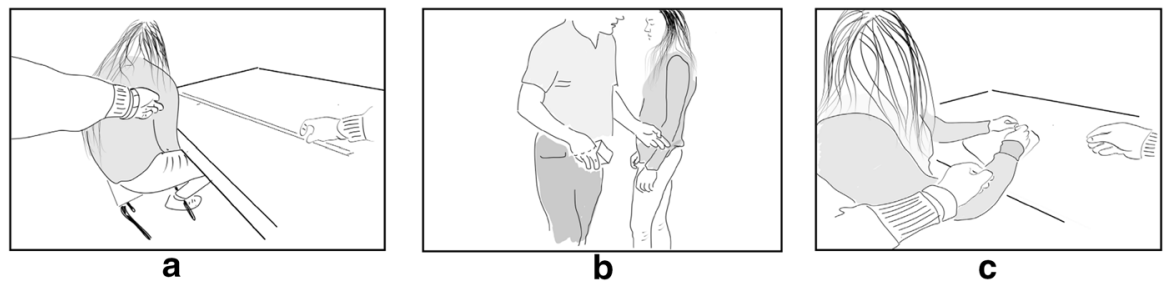

Fig. 9 a-c Don's join-my-path nudges 


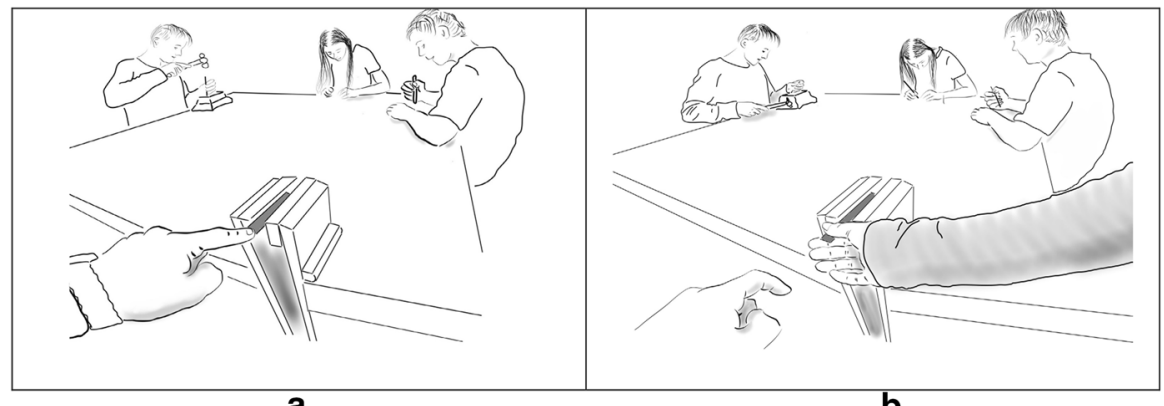

a

b

Fig. 10 a, b Striking the drill hole as a way of reaching agreement about the next course of action

the pupils to selectively attend to immediate experienced qualities and to create tuning in opportunities.

The next example illustrates an accentuated form of sensing along, here known as 'lending a hand'. Don mediates his immediately experienced quality of a sharp edge and shares the experience of "too sharp" by putting the piece of steel into the pupil's hand at a certain angle and applying a little pressure (Fig. 11a). What happens next is that the pupil probes the technique of sensing "too sharp" on her own (Fig. 11b) as a direct consequence of the educational nudge of sensing along.

Don uses the sensing along technique in various situations to share specific experiences in the rhythm of activities. For instance, in the environment of carving a wooden plate (Fig. 12a), Don makes use of a pupil's hands in the same way as he uses his own to experience the rough texture around the carved letters. He moves the pupil's hand across an area of the plate to facilitate discovery of the "not deep enough" texture that he has identified. In Fig. 12b, Don 'lends a hand' and uses the pupil's index finger as a tool to detect the roughness in a particular part of the wooden plate, which for the pupil becomes an embodied, immanent (i.e., sense) meaning.

With all the fine motoric complexities of power of pressure, degrees of angles and speed of movement, the "sharpness" of steel or the "roughness" of wood is detected as Don and the pupils move their hands and fingers in certain ways over certain parts of the material. Again, shared experience is aimed at by educationally

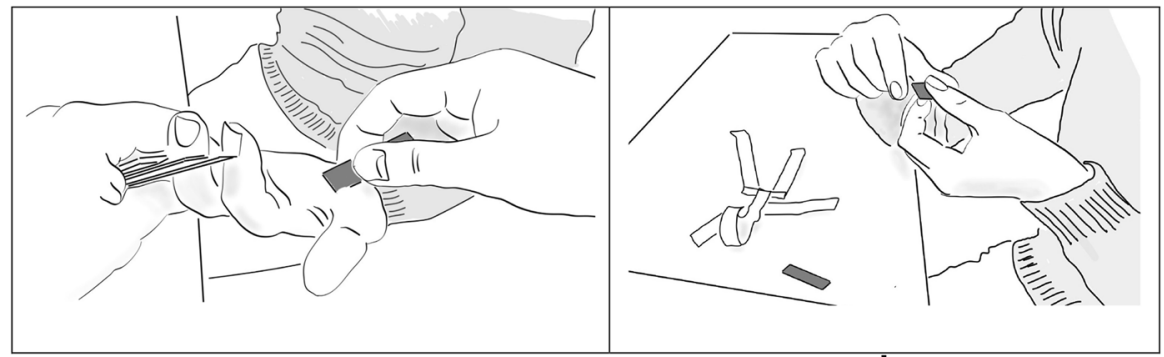

a

b

Fig. 11 a, b 'Lending a hand' and the subsequent act of probing 'sharpness' 


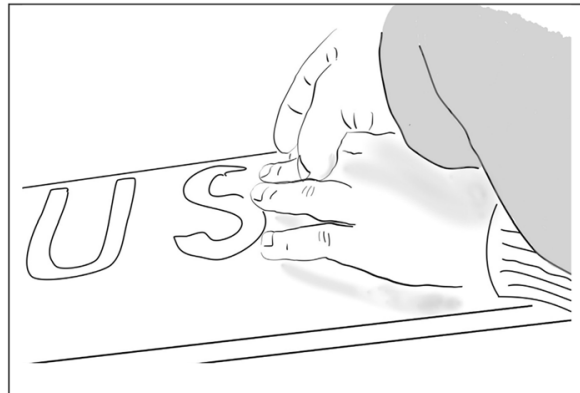

a

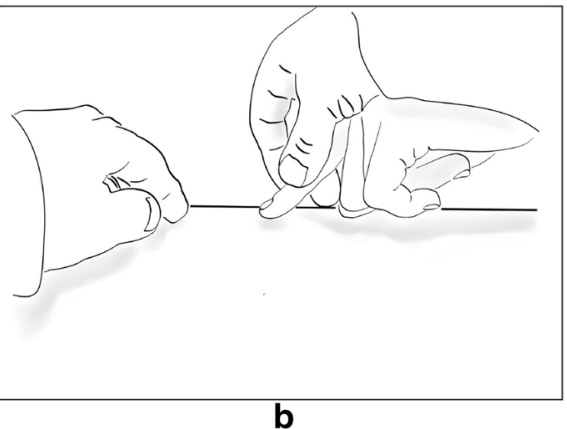

b

Fig. 12 a, b 'Lending a hand' as an 'educational nudge' to reach agreement about the next course of action

nudging the pupils in a recommended direction by sensing along. As pacts, that "sharpness" and that "roughness" are embodied outcomes of actions performed in a certain path and pace and serve as reference points, both in the continuing rhythm of the walking teaching and in further teacher-pupil encounters.

In the last example, Don and a pupil create a pact about the drilling of a hole. When Don enters the pupil's field of vision the machine is set up (drill size, drill fastened and speed adjustments) and the plate (to drill in) is fastened in. In this situation, the 'educational nudge' centres on experiencing the immediate quality of the required drilling speed and pressure. The image below shows how Don executes the technique together with the pupil. By "tooling" together for some seconds, this 'nudge' enables the pupil to tune into a recommended course of action and drill by herself using the correct drilling speed (Fig. 13).

In a walking teaching environment, pacts are often reached quickly and easily through the embodied arrangements of educational nudges. Putting the analytical spotlight on different pacts illustrates how Don and the pupils create different ways of sharing experience and forming recommended courses of action (outcomes).

Fig. 13 Finding the right drilling speed

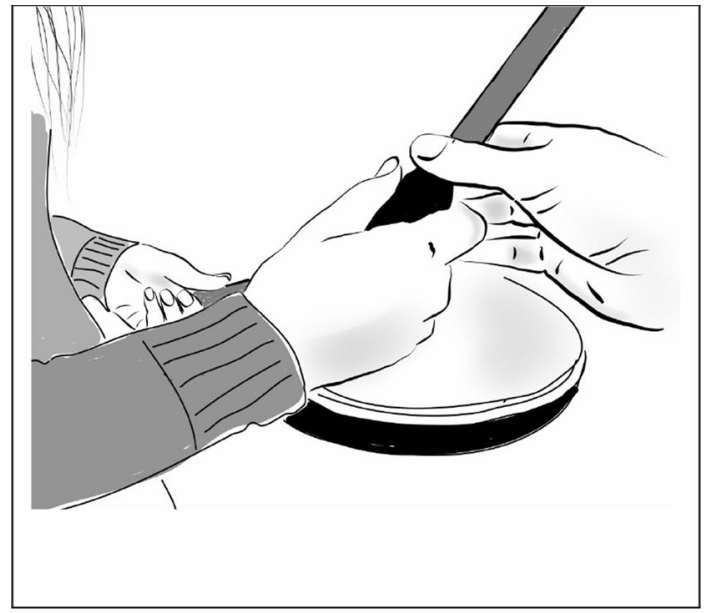


Educational 'nudges' are swiftly performed actions that are easy to assimilate into the bodily capacity of moving in a sloyd classroom. As distinctive educational means, educational nudges are brief and make distraction and dispersion (hundreds of 'stops-and-starts') as dynamic as possible. A typical 'join-my-path' nudge indicates how to move in the workshop and how to tune into a collective crafting rhythm. 'Sensing along' (by "lending a hand" or "tooling") shows how to probe material (metal plate), a product (the aesthetic roughness of a wooden plate) and a tool (drilling).

However, an educational nudge does not always result in mutual agreement. It can only have an educative outcome as a pact when the rhythm of the other facilitates the rhythm of the self and becomes a reference to rely on. However, whether or not the right judgements are made or the right qualities experienced, the pact unites in an agreement about using the body to engage in the crafting process.

\section{Discussion}

Movement and rhythm as modes of analysis are as yet unexplored in body pedagogics in general and in classroom research in particular. Sloyd education offers a classroom environment that is infused with bodily engagement and changing social, material and instructional conditions, which challenge the teacher to find ways to channel pupils' experiences into ordered interest. We argue that this ordered interest is beneficially understood as a certain craft learning rhythm.

By pursuing a GoPro view of sloyd education in the classroom and using a pragmatist informed analytical framework of experience and habit, we have shown how Don's and the pupils' embodied engagement establishes communicational structures (by tuning into path and pace) and micro learning environments (by establishing pacts). Don engages in the pupils' assignments in various ways, which are conditioned by his walking teaching. This walking teaching rhythm is an outcome of a reciprocal relationship between the pupils' needs and Don's movement habits.

Analytically, pathing, pacing and pacting constitute three levels of engagement in Don's sloyd teaching. These different engagements are all made possible by a skilful rhythmic way of traversing an educational terrain. The 'path' visualises how Don and the pupils spatially interact and position themselves in relation to each other and to the material conditions and explains how Don's walking teaching associates with a continuous flow of transposition. The 'pace' accentuates the scattered array of focused encounters and explains that although not necessarily tense or problematic, every 'stop' (focused encounter) exhibits certain pervasive qualities that hang together in certain ways and are direct. To initialise, expand and end a lesson requires pupils to tune into path and pace. A pact is a time and a place in which Don's walk intersects with pupils' purposes. In this sense, pacts visualise how rhythms of 'the other' make rhythms of 'the self' possible or impossible.

A second result is the identification of 'educational nudges' as teaching tools. In this article, the analysis of educational nudges is restricted to embodied aspects of the creation of pacts. Don's endured habit of moving in and through the workshop 
classroom, as well as how and when the pupils address him, relates to specific educational nudges (pedagogical means) such as "join my path", "lending a hand" and "collective tooling". The body pedagogics outcome is a purposeful alternation between tutoring the pupils and doing it for them.

A third result is Don's alternation between adhering to the "the full richness" of the craft learning rhythm of the class by his way of walking and engaging in "innovative thinking" and reflexive thought according to individual pupil assignments. Considering his walk as a distinctive teaching tool, in Deweyan vocabulary he alters between consummating the tool (walking the 'walk') and enriching the tool (talking the 'talk') to guide the pupils in their craft processes.

In developing a research programme for rhythm analysis, Lefebvre (2004) claims "every gathering of bodies is consequently polyrhythmic, which is to say composed of diverse rhythms, with each part, each organ or function having its own in a perpetual interaction that constitutes a set or a whole" (p. 89). 'Pact' refers to the activity of creating a shared purpose of a recommended course of action in a spatial-temporal rhythm and constitutes a focused interest in the plurality of rhythms which is made possible by bodily movement. Despite this, if we only recognise the creation of pacts as the educational important process, we may neglect situations and actions that are not part of face-to-face interaction or reflexive thought. This would rob education of every experience of the rhythm of perchings and flights, which constitutes the very conditions for learning as a practical concern.

Finally we draw attention to how the body technique of nudging pupils in sloyd education actualises questions about the ambiguity of intergenerational touch (Piper and Smith 2003) and how techniques of bodily touch exist in the intersection between public moral discourse and carrying out a persona/professional call to teach (Andersson et al. 2016).

Acknowledgements Thanks to colleagues on the Teaching and Learning Practical Embodied Knowledge Project based at the University of Uppsala and funded by The Swedish Research Council.

Open Access This article is distributed under the terms of the Creative Commons Attribution 4.0 International License (http://creativecommons.org/licenses/by/4.0/), which permits unrestricted use, distribution, and reproduction in any medium, provided you give appropriate credit to the original author(s) and the source, provide a link to the Creative Commons license, and indicate if changes were made.

\section{References}

Almquist, J., \& Quennerstedt, M. (2015). Is there (any)body in science education? Interchange, 46(4), 439-453. https://doi.org/10.1007/s10780-015-9264-4.

Amade-Escot, C. (2006). Student learning within the didactique tradition. In D. Kirk, M. O'Sullivan, \& D. Macdonald (Eds.), Handbook of research in physical education (pp. 347-365). Thousand Oaks, CA: Sage.

Andersson, J., \& Garrison, J. (2016). Embodying meaning-Qualities, feelings, selective attention, and habits. Quest, 68(2), 207-222. 
Andersson, J., \& Maivorsdotter, N. (2016). The 'body pedagogics' of an elite footballer's career pathAnalysing Zlatan Ibrahimovic's biography. Physical Education and Sport Pedagogy. https://doi.org/ 10.1080/17408989.2016.1268591.

Andersson, J., Öhman, M., \& Garrison, J. (2016). Physical education teaching as a caring actTechniques of bodily touch and the paradox of caring. Sport, Education and Society. https://doi.org/ $10.1080 / 13573322.2016 .1244765$.

Andersson, J., \& Östman, L. (2015). A transactional way of analysing the learning of 'tacit knowledge'. Interchange, 46(3), 271-287. https://doi.org/10.1007/s10780-015-9252-8.

Andersson, J., Östman, L., \& Öhman, M. (2015). I am sailing-Towards a transactional analysis of body techniques'. Sport, Education and Society, 20(6), 722-740. https://doi.org/10.1080/13573322.2013. 802684.

Bernstein, B. (1990). Class, codes and control: The structuring of pedagogic discourse (Vol. 4). London: Routledge.

Birdwhistell, R. (1970). Kinetics and contex: Essays on body motion communication. Philadelphia: University of Pennsylvania Press.

Brown, S. D., Cromby, J., Harper, D. J., Johnson, K., \& Reavey, P. (2011). Researching "experience": Embodiment, methodology, process. Theory \& Psychology, 21(4), 493-515.

Brown, T. D., \& Payne, P. G. (2009). Conceptualizing the phenomenology of movement in physical education: Implications for pedagogical inquiry and development. Quest, 61(4), 418-441.

Calhoun, C., \& Sennett, R. (Eds.). (2007). Practicing culture. New York: Routledge.

Chalfen, R. (2014). Your panopticon or mine? Incorporating wearable technology's Glass and GoPro into visual social science. Visual Studies, 29(3), 299-310. https://doi.org/10.1080/1472586X.2014. 941547.

Charalampous, K., \& Kokkinos, C. M. (2013). The Model of Interpersonal Teacher Behaviour: a qualitative cross-cultural validation within the Greek elementary education context. British Educational Research Journal, 39(1), 182-205.

Clarke, D., Keitel, C., \& Shimizu, Y. (2006). Mathematics classrooms in twelve countries: The insider's perspective (Vol. 1). Rotterdam: Sense Publishers.

Crossley, N. (2004). The circuit trainer's habitus: Reflexive body techniques and the sociality of the workout. Body \& Society, 10(1), 37-69. https://doi.org/10.1177/1357034X04041760.

Crossley, N. (2005). Mapping reflexive body techniques: On body modification and maintenance. Body \& Society, 11(1), 1-35. https://doi.org/10.1177/1357034X05049848.

Crossley, N. (2006). Reflexive embodiment in contemporary society. New York: Open University Press.

Crossley, N. (2007). Researching embodiment by way of 'body techniques. The Sociological Review, 55(s1), 80-94.

Derry, S. J., Pea, R. D., Barron, B., Engle, R. A., Erickson, F., Goldman, R., et al. (2010). Conducting video research in the learning sciences: Guidance on selection, analysis, technology, and ethics. The Journal of the Learning Sciences, 19(1), 3-53.

Dewey, J. (1934/2005). Art as experience. New York: Penguin.

Dewey, J. (1958). Experience and nature. New York: Dover.

Doyle, W. (1977). Paradigms for research on teacher effectiveness. In L. S. Shulman (Ed.), Review of research in education (pp. 163-198). Itasca, IL: F.E. Peacock Publisher.

Doyle, W. (1986). Classroom organization and management. In M. C. Wittrock (Ed.), Handbook of Research on Teaching (3rd ed., pp. 392-431). New York: Macmillan.

Edensor, T. (2010). Walking in rhythms: Place, regulation, style and the flow of experience. Visual Studies, 25(1), 69-79. https://doi.org/10.1080/14725861003606902.

Evans, J., Davies, B., \& Rich, E. (2009). The body made flesh: Embodied learning and the corporeal device. British Journal of Sociology of Education, 30(4), 391-406.

Evans, J., Rich, E., Allwood, R., \& Davies, B. (2008). Body pedagogies, P/policy, health and gender. British Educational Research Journal, 34(3), 387-402. https://doi.org/10.1080/ 01411920802042812.

Fisher, R. (2012). Teaching writing: A situated dynamic. British Educational Research Journal, 38(2), 299-317. https://doi.org/10.1080/01411926.2010.544711.

Franks, A., \& Jewitt, C. (2001). The meaning of action in Learning and Teaching. British Educational Research Journal, 27(2), 201-218.

Garrison, J. (2001). An introduction to Dewey's theory of functional "transaction": An alternative paradigm for activity theory. Mind, Culture, and Activity, 8(4), 275-296. 
Garrison, J. (2009). Dewey's constructivism: From the reflex arc concept to social constructivism. In L. Hickman, S. Neubert, \& K. Reich (Eds.), John Dewey between pragmatism and constructivism (pp. 84-105). New York: Fordham University Press.

Garrison, J. (2011). Walt Whitman, John Dewey, and primordial artistic communication. Transactions of the Charles S. Peirce Society: A Quarterly Journal in American Philosophy, 47(3), 301-318.

Garrison, J. (2015). Dewey's aesthetics of body-mind functioning. In A. Scarinzi (Ed.), Aesthetics and the embodied mind: Beyond art theory and the Cartesian mind-body dichotomy (pp. 39-53). Dordrecht: Springer.

Goldman, R., Pea, R., Barron, B., \& Derry, S. (2007). Video research in the learning sciences. Mahwah, NJ: Lawrence Erlbaum Associates.

Håkansson, M., \& Östman, L. (forthcoming). Politics and the political dimension in ESE: The construction of an analytical model of political moment. Environmental Education Research.

Hassard, J., Holliday, R., \& Willmott, H. (Eds.). (2000). Body and organization. London: Sage.

Hastie, P.-A., \& Siedentop, D. (2006). The classroom ecology paradigm. In D. Kirk, D. MacDonald, \& M. O'Sullivan (Eds.), The handbook of physical education (pp. 214-225). Thousands Oaks, CA: Sage.

Heath, C., Hindmarsh, J., \& Luff, P. (2010). Video in qualitative research. Los Angeles: Sage.

Hester, S. K., \& Francis, D. (Eds.). (2000). Local educational order: Ethnomethodological studies of knowledge in action (Vol. 73). Amsterdam: John Benjamins Publishing.

Hickman, L. (1992). John Dewey's pragmatic technology. Bloomington: Indiana University Press.

Hockey, J., \& Allen-Collinson, J. (2007). Grasping the phenomenology of sporting bodies. International Review for the Sociology of Sport, 42(2), 115-131. https://doi.org/10.1177/1012690207084747.

Illum, B. (2006). Learning in practice-practical wisdom-the dialogue of the process. Journal of Research in Teacher Education. Theme: Slojd Tradition in Transition, 16(2-3), 106-127.

Illum, B., \& Johansson, M. (2009). Vad är tillräckligt mjukt? kulturell socialisering och lärande iskolans slöjdpraktik. FORMakademisk, 2(1), 69-82.

James, W. (1884). What is an emotion? Mind, 9(34), 188-205.

Janík, T., Seidel, T., \& Najvar, P. (Eds.). (2009). The power of video studies in investigating teaching and learning in the classroom. Münster: Waxmann.

Joas, H. (1996). The creativity of action. Chicago: University of Chicago Press.

Johnson, M. (2007). The meaning of the body: Aesthetics of human understanding. Chicago: University of Chicago Press.

Lakoff, G., \& Johnson, M. (1999). Philosophy in the flesh: The embodied mind and its challenge to western thought. New York: Basic Books.

Lande, B. (2007). Breathing like a soldier: Culture incarnate. The Sociological Review, 55(S1), 95-108. https://doi.org/10.1111/j.1467-954X.2007.00695.

Larsson, H., \& Quennerstedt, M. (2012). Understanding movement: A sociocultural approach to exploring moving humans. Quest, 64(4), 283-298.

Lave, J. (2011). Apprenticeship in critical ethnographic practice. Chicago: University of Chicago Press.

Lave, J. (2012). Changing practice. Mind, Culture, and Activity, 19(2), 156-171. https://doi.org/10.1080/ 10749039.2012 .666317$.

Lefebvre, H. (2004). Rhythmanalysis: Space, time and everyday life. London: A\&C Black.

Leriche, J., Desbiens, J. F., Amade-Escot, C., \& Tinning, R. (2016). Compatibility and complementarity of classroom ecology and didactique research perspectives in physical education. Quest, 68(4), 497-520. https://doi.org/10.1080/00336297.2016.1144516.

Lloyd, M. (2016). 'It's on video, every second of it': A micro-sociological analysis of cycle rage. Visual Studies, 31(3), 206-220. https://doi.org/10.1080/1472586X.2016.1209986.

Maivorsdotter, N., \& Wickman, P.-O. (2011). Skating in a life context: Examining the significance of aesthetic experience in sport using practical epistemology analysis. Sport, Education and Society, 16(5), 613-628.

Marchand, T. H. J. (2008). Muscles, morals and mind: Craft apprenticeship and the formation of person. British Journal of Educational Studies, 56(3), 245-271. https://doi.org/10.1111/j.1467-8527.2008. 00407.

Marchand, T. H. J. (2010a). Making knowledge: Explorations of the indissoluble relation between minds, bodies, and environment. Journal of the Royal Anthropological Institute, N.S., S1-S21.

Marchand, T. H. J. (2010b). Embodied cognition and communication: Studies with British fine woodworkers. Journal of the Royal Anthropological Institute, N.S., S100-S120.

McDowell, L. (2011). Working bodies: Interactive service employment and workplace identities (Vol. 61). Oxford: Wiley. 
Mehan, H. (1979). Learning lessons. Cambridge, MA: Harvard University Press.

Mehan, H. (1998). The study of social interaction in educational settings: Accomplishments and unresolved issues. Human development, 41(4), 245-269.

Mellor, P. A., \& Shilling, C. (2010). Body pedagogics and the religious habitus: A new direction for the sociological study of religion. Religion, 40(1), 27-38.

Mellor, P. A., \& Shilling, C. (2014). Sociology of the sacred: Religion, embodiment and social change. Thousand Oaks, CA: Sage.

Mondada, L. (2006). Video recording as the reflexive preservation and configuration of phenomenal features for analysis. In H. Knoblauch, B. Schnettler, J. Raab, \& H. G. Soeffner (Eds.), Video analysis: Methodology and methods (pp. 51-68). Oxford: Peter Lang.

Morais, A. M. (2002). Basil Bernstein at the micro level of the classroom. British Journal of Sociology of Education, 23(4), 559-569. https://doi.org/10.1080/0142569022000038413.

Nielsen, K., \& Kvale, S. (1999). Mesterlaere: Laering som sosial praksis.

O'Connor, E. (2007). Embodied knowledge in glassblowing: The experience of meaning and the struggle towards proficiency. The Sociological Review, 55(suppl 1), 126-141.

Ochs, E., Graesch, A. P., Mittmann, A., Bradbury, T., \& Repetti, R. (2006). Video ethnography and ethnoarchaeological tracking. In M. Pitt-Catsouphes, E. E. Kossek, \& S. Sweet (Eds.), The work and family handbook: Multi-disciplinary perspectives, methods, and approaches (pp. 387-409). Mahwah, NJ: Lawrence Erlbaum Associates Publishers.

Pierre, A., \& Macleod, G. (2010). Tripping, slipping and losing the way: Moving beyond methodological difficulties in social research. British Educational Research Journal, 36(3), 367-378.

Pink, S. (2011). From embodiment to emplacement: Re-thinking competing bodies, senses and spatialities. Sport, Education and Society, 16(3), 343-355.

Piper, H., \& Smith, H. (2003). 'Touch' in educational and child care settings: Dilemmas and responses. British Educational Research Journal, 29(6), 879-894. https://doi.org/10.1080/ 0141192032000137358.

Plowman, L., \& Stephen, C. (2008). The big picture? Video and the representation of interaction. British Educational Research Journal, 34(4), 541-565.

Psathas, G. (1995). Conversation analysis: The study of talk-in-interaction (Vol. 35). Thousand Oaks, CA: Sage.

Quennerstedt, M. (2013). Practical epistemologies in physical education practice. Sport, Education and Society, 15(2), 147-150.

Quennerstedt, M., Öhman, J., \& Öhman, M. (2011). Investigating learning in physical education: A transactional approach. Sport, Education and Society, 16(2), 159-177.

Ryan, M. (2011). Productions of space: Civic participation of young people at university. British Educational Research Journal, 37(6), 1015-1031.

Scheper-Hughes, N., \& Wacquant, L. (2002). Commodifying bodies (Vol. 7). London: Sage. ISBN 9781849206600 .

Sennett, R. (1998). The corrosion of character: The transformation of work in modern capitalism. New York and London: Norton Company.

Sennett, R. (2008). The craftsman. Yale University Press.

Sheets-Johnstone, M. (2011). The primacy of movement (Vol. 82). Amsterdam: John Benjamins Publishing.

Sheflen, A. (1972). Communicational structure. Bloomington, IN: Indiana University Press.

Shilling, C. (2004). Physical capital and situated action: A new direction for corporeal sociology. British Journal of Sociology of Education, 25(3), 473-487.

Shilling, C. (2005). The body in culture, technology \& society. London: Sage Press/Theory, Culture \& Society.

Shilling, C. (2007). Sociology and the body: Classical traditions and new agendas. The Sociological Review, 55(S1), 1-18. https://doi.org/10.1111/j.1467-954X.2007.00689.

Shilling, C. (2008). Changing bodies: Habit, crisis and creativity. London: Sage.

Shilling, C. (2010). Exploring the society-body-school nexus: Theoretical and methodology issues in the study of body pedagogics. Sport, Education and Society, 15(2), 151-167. https://doi.org/10.1080/ 13573321003683786.

Shilling, C. (2012). The body and social theory (3rd ed.). London: Sage Press.

Shilling, C. (2017). Body pedagogics: Embodiment, cognition and cultural transmission. Sociology, 51(6), 1205-1221. 
Shilling, C. (2018). Embodying culture: Body pedagogics, situated encounters and empirical research. The Sociological Review, 66(1), 75-90.

Sigurdsson, E. (2014). Det sitter $i$ väggarna. En studie av trä- och metallslöjdsalens materialitet, maskulinitet och förkroppsliganden. Dissertation, Umeå University, Umeå.

Stivers, T., \& Sidnell, J. (2005). Introduction: Multimodal interaction. Semiotica, 2005(156), 1-20.

Sullivan, S. (2001). Living across and through skins-Transactional bodies, pragmatism and feminism. Bloomington, IN: Indiana University Press.

Swedish National Agency for Education. (2011). Curriculum for the compulsory school, preschool class and the recreation centre. Stockholm: Ordförrådet $\mathrm{AB}$.

Todres, L. (2007). Embodied enquiry: Phenomenological touchstones for research, psychotherapy and spirituality. Dordrecht: Springer.

Wacquant, L. (2004). Body and soul: Notebooks of an apprentice boxer. Oxford: Oxford University Press. 